\title{
How to walk the tightrope between harm and protection in selecting the optimal antiplatelet treatment strategy after transcatheter left atrial appendage occlusion
}

\author{
Radosław Pracoń, Marcin Demkow \\ Coronary and Structural Heart Diseases Department, Institute of Cardiology, Warsaw, Poland
}

Postep Kardiol Inter 2015; 11, 1 (39): 5-8 DOI: $10.5114 /$ pwki.2015.49177

The left atrial appendage (LAA) conceals $90 \%$ of thrombi found in the left atrium in patients with atrial fibrillation (AF), and thus has been declared the main villain responsible for thromboembolic events associated with AF [1]. Systemic anticoagulation cuts the risk of stroke and peripheral embolism associated with $A F$ by more than $60 \%[2,3]$. However, it is a double-edged sword, as it carries a substantial bleeding risk [4]. The bleedings affect tissues and organs located far from the LAA - innocent bystanders, one could say. Hence, it seems perfectly reasonable to call for a local solution to a local problem, without putting patients at risk of systemic complications. In response to this call the concept of mechanical closure of the LAA (LAAC) has appeared $[5,6]$. The concept proved to be at least as effective as anticoagulation with vitamin $\mathrm{K}$ antagonists in randomised and non-randomised studies with the two CE marked left atrial appendage occluders available on the market: the WATCHMAN Device and the Amplatzer Cardiac Plug (ACP) Device [7-13]. It was suggested that LAAC would show its full potential in delivering net clinical benefit over vitamin $\mathrm{K}$ antagonists at longer-term follow-ups, after having left behind early hazards of the implantation procedure and with continuous accumulation of adverse events with anticoagulation. Indeed, in a very recent landmark report with 3.8-years follow-up of patients from the initial PROTECT AF trial, the WATCHMAN device has met superiority criteria over warfarin in reducing combined outcome, including thromboembolic events. What is even more momentous, WATCHMAN proved superior in reducing cardiovascular as well as all-cause mortality [14]. Still, the body of evidence on this relatively novel technology is scarce when compared to extensive data on the effi- cacy and safety of oral anticoagulation, including novel drugs. Furthermore, the technology itself is still young and the procedure carries inherent risks that are partly mitigated with growing operators' experience. The current European guidelines recommend that this procedure should be limited to AF patients at high stroke risk and with contraindications to anticoagulation [15].

The guidelines, however, do not address the issue of the scope and duration of antiplatelet treatment after successful elimination of the LAA. This issue remains unresolved, as no systematic or randomised data comparing various treatment strategies have been published so far. Before such data become available we can only rely on pathophysiological reasoning and extrapolations from the available literature or clinical practice in order to deliver the best quality care for our patients and also to better design future clinical trials to resolve this matter.

If we consider patients after LAAC with no other indications to antiplatelet therapy except for AF and the procedure itself, platelet inhibition has two major merits. The first one is to prevent thrombus formation on the occluder before its endothelialisation, with dual antiplatelet regimen being advised for this indication. The second one is to prevent cardio- and cerebrovascular complications, mainly as a primary prevention measure, with lifelong antiplatelet monotherapy being considered for this indication.

With regards to preventing formation of a thrombus on the occluder, there has been broad and long-standing clinical experience with the Amplatzer family of septal occluders. Three to 6 months of antiplatelet therapy is usually recommended following implantation of this type of device.

\section{Corresponding author:}

Radosław Pracoń MD, PhD, Coronary and Structural Heart Diseases Department, Institute of Cardiology, 42 Alpejska St, 04-628 Warsaw, Poland, phone: +48 504211 12, e-mail: radekpracon@yahoo.pl

Received: 2.02.2015, accepted: 2.02.2015. 
The treatment is thought to constitute a buffer against clot formation on the surface of the implant before its endothelialisation. The healing response to such nitinol-based, polyester-covered occluders was shown to be initiated by the formation of thrombotic material within the device structure and then its transformation into connective tissue $[16,17]$. The neoendothelium and pseudointima cover the device surface almost fully after 4 weeks, although complete device coverage may take more than 24 months; this is very often long after cessation of all antiplatelet agents [17, 18]. Despite the presence of exposed parts of the device in patients without any platelet inhibiting therapy, late clot formation on these occluders has not posed any significant clinical problem. Moreover, it may even be hypothesised that antiplatelets inhibit fibrin formation in the early stages of device healing and thus delay its endocardialisation. Despite the fact that ACP is made of the same fabric as septal occluders, it has a different design, location, and purpose. It is also implanted in a much older population of patients, presenting with many co-morbidities. So we need extra caution when extrapolating data regarding periprocedural antiplatelet treatment from septal occluders to the ACP. There is one short report on healing responses after LAAC in the canine model. It showed that after 28 days from implantation the WATCHMAN device was completely neo-endothelialised. The ACP still showed spots of incomplete neointimal coverage, though without any evidence of overlying thrombus [19].

In the published registries, prospective studies, and in clinical practice various dual antiplatelet therapy (DAPT) duration regimens after LAAC are applied and range most often from 1 to 6 months. There is no strong evidence to suggest that the duration of DAPT is related either to clot formation on the device or cerebrovascular events. The reported incidence of device thrombus formation ranges most often from $2 \%$ to $5 \%$, and the associated stroke event rates are as low as $0.3 \%$ to $0.7 \%[5,8-10$, 18]. Conversely, as demonstrated by the ACTIVE trial, the addition of clopidogrel on top of aspirin, compared with aspirin alone, resulted in a significant increase in major bleeding rates $(2.0 \%$ vs. $1.3 \%$ per year, respectively) in patients with AF [20]. In the recently published DAPT trial, which randomised patients after percutaneous coronary intervention to 12 vs. 18 months of DAPT, episodes of moderate or severe bleeding were significantly more frequent in the latter group ( $2.5 \%$ vs. $1.6 \%$, respectively, $p=$ 0.001 ). Bleeding risks with dual antiplatelet therapy are expected to be much more pronounced in the population of patients at high baseline bleeding risk, such as after LAAC.

To conclude this part, with evidence of significant increase in major bleeding risk and no apparent benefit with longer DAPT, it seems prudent to keep DAPT after LAAC short. Caution should be exercised though with reg- ular follow-up imaging to exclude thrombus formation on the occluding device, at least until more systematic data on this issue becomes available. In the meantime, EHRA/ EAPCI expert consensus statement on catheter-based left atrial appendage closure recommends a wide range of 1 to 6 months of DAPT after the procedure [21].

The second objective to use antiplatelet agents after LAAC is primary or secondary prevention of cardioembolic events. Aspirin has been extensively studied in patients with AF. Overall, no significant benefit has been noted in terms of cerebrovascular event reduction. In a meta-analysis involving 8 trials (4876 participants) a relative 19\% $(95 \% \mathrm{Cl}-1 \%$ to $-35 \%)$ reduction in the incidence of stroke was shown [22]. Aspirin efficacy was even lower in patients over 75 years of age, and the observed modest efficacy has been attributed more to its effects on atherosclerotic vascular disease than AF related thrombus formation. It is important to note that the cohorts studied included patients with overt vascular atherosclerotic disease. As a matter of fact, in patients with AF, the bleeding risk with aspirin is similar to the risk posed by vitamin $\mathrm{K}$ antagonists or novel oral anticoagulants, and is about 4-fold greater than in untreated controls [23-25]. In the AVERROES trial, which randomised warfarin-unsuitable patients to receive either aspirin or apixaban, the incidence of major bleeding was similar between the two treatment arms (1.4\% for apixaban and 1.2\% for aspirin) [24]. Episodes of intracranial bleedings were also similar in each arm of AVERROES, even numerically higher in the aspirin group. In the elderly population, the risk of adverse events including serious bleedings has been shown to be significantly greater with moderate-dose aspirin as compared to warfarin (33\% vs. $6 \%$, respectively) [26]. Consequently, because of its modest efficacy and serious risks, aspirin is not a good choice to prevent cardioembolic events associated with AF.

Arguments have been raised that the population of patients after LAAC is elderly and often present with atherosclerosis even in the absence of its overt sings or symptoms, and so aspirin would be a good option to reduce atherothrombotic complications. Nonetheless, large studies of aspirin in primary prevention fail to show any net clinical benefit even after the inclusion of colorectal cancer risk reduction effects [27-29]. On the contrary, aspirin-treated patients very often show worse outcomes. Again this is explained by the significant bleeding risk with aspirin, which may be even more pronounced in the population of patients with AF. This holds true especially for those at high baseline bleeding risk, and patients after LAAC surely belong to this group. The European Society of Cardiology guidelines do not recommend antiplatelet therapy in patients without overt cardio- or cerebrovascular disease (class III level of evidence B) [30].

It seems reasonable to hypothesise that patients after LAAC, without overt atherosclerotic disease, mostly elder- 
ly, at high bleeding risk, may be better off on short-term rather than lifelong antiplatelet monotherapy. The EHRA/ EAPCI expert consensus statement on catheter-based left atrial appendage closure is of little help here. Its advice is rather general and nonspecific, stating that after completion of a post-procedural DAPT course, patients should be prescribed aspirin or clopidogrel monotherapy lifelong or no antiplatelets at all.

There is equipoise in clinical practice concerning the scope and duration of antiplatelet treatment following LAAC. Given the substantial bleeding risks posed by treatment with antiplatelet agents in the population of patients after LAAC, platelet-inhibiting therapy should be chosen with great caution. In-depth, randomised data on the subject remains a burning, unmet need.

\section{Conflict of interest}

The authors declare no conflict of interest.

\section{References}

1. Blackshear JL, Odell JA. Appendage obliteration to reduce stroke in cardiac surgical patients with atrial fibrillation. Ann Thorac Surg 1996; 61: 755-9.

2. Hart RG, Pearce LA, Aguilar MI. Meta-analysis: antithrombotic therapy to prevent stroke in patients who have nonvalvular atrial fibrillation. Ann Intern Med 2007; 146: 857-67.

3. Ruff CT, Giugliano RP, Braunwald E, et al. Comparison of the efficacy and safety of new oral anticoagulants with warfarin in patients with atrial fibrillation: a meta-analysis of randomised trials. Lancet 2014; 383: 955-62.

4. Pisters R, Lane DA, Nieuwlaat R, et al. A novel user-friendly score (HAS-BLED) to assess 1-year risk of major bleeding in patients with atrial fibrillation: the Euro Heart Survey. Chest 2010; 138: 1093-100.

5. Ostermayer SH, Reisman M, Kramer PH, et al. Percutaneous left atrial appendage transcatheter occlusion (PLAATO system) to prevent stroke in high-risk patients with non-rheumatic atrial fibrillation: results from the international multi-center feasibility trials. J Am Coll Cardiol 2005; 46: 9-14.

6. Kukula K, Klopotowski M, Konka M, et al. Left atrial appendage occlusion using the PLAATO system in high-risk patients with atrial fibrillation - long-term follow-up. Postep Kardiol Inter 2009; 5: 51-7.

7. Park JW, Bethencourt A, Sievert H, et al. Left atrial appendage closure with Amplatzer cardiac plug in atrial fibrillation: initial European experience. Catheter Cardiovasc Interv 2011; 77: 700-6.

8. Reddy VY, Holmes D, Doshi SK, et al. Safety of percutaneous left atrial appendage closure: results from the watchman left atrial appendage system for embolic protection in patients with AF (PROTECT AF) clinical trial and the continued access registry. Circulation 2011; 123: 417-24.

9. Reddy VY, Doshi SK, Sievert H, et al. Percutaneous left atrial appendage closure for stroke prophylaxis in patients with atrial fibrillation: 2.3-year follow-up of the PROTECT AF (watchman left atrial appendage system for embolic protection in patients with atrial fibrillation) trial. Circulation 2013; 127: 720-9.

10. Lam YY, Yip GW, Yu CM, et al. Left atrial appendage closure with AMPLATZER cardiac plug for stroke prevention in atrial fibrilla- tion: initial Asia-pacific experience. Catheter Cardiovasc Interv 2012; 79: 794-800.

11. Lopez-Minguez JR, Eldoayen-Gragera J, Gonzalez-Fernandez R, et al. Immediate and one-year results in 35 consecutive patients after closure of left atrial appendage with the Amplatzer cardiac plug. Rev EspCardiol (Engl Ed) 2013; 66: 90-7.

12. Streb W, Szymala M, Kukulski T, et al. Percutaneous closure of the left atrial appendage using the Amplatzer cardiac plug in patients with atrial fibrillation: Evaluation of safety and feasibility. Kardiol Pol 2013; 71: 8-16.

13. Holmes DR Jr, Kar S, Price MJ, et al. Prospective randomized evaluation of the watchman left atrial appendage closure device in patients with atrial fibrillation versus long-term warfarin therapy: the PREVAIL trial. J Am Coll Cardiol 2014; 64: 1-12.

14. Reddy VY, Sievert H, Halperin J, et al. Percutaneous left atrial appendage closure vs. warfarin for atrial fibrillation: a randomized clinical trial. JAMA 2014; 312: 1988-98.

15. Camm AJ, Lip GY, De Caterina R, et al. 2012 focused update of the ESC guidelines for the management of atrial fibrillation: an update of the 2010 ESC guidelines for the management of atrial fibrillation: developed with the special contribution of the European Heart Rhythm Association. Europace 2012; 14: 1385-413.

16. Sigler M, Jux C. Biocompatibility of septal defect closure devices. Heart 2007; 93: 444-9.

17. Foth R, Quentin T, Michel-Behnke I, et al. Immunohistochemical characterization of neotissues and tissue reactions to septal defect-occlusion devices. Circ Cardiovasc Interv 2009; 2: 90-6.

18. Chen F, Zhao X, Zheng $X$, et al. Incomplete endothelialization and late dislocation after implantation of an Amplatzer septal occluder device. Circulation 2011; 124: e188-9.

19. Kar S, Hou D, Jones R, et al. Impact of watchman and amplatzer devices on left atrial appendage adjacent structures and healing response in a canine model. JACC Cardiovasc Interv 2014; 7: 801-9.

20. ACTIVE Investigators, Connolly SJ, Pogue J, Hart RG, et al. Effect of clopidogrel added to aspirin in patients with atrial fibrillation. N Engl J Med 2009; 360: 2066-78.

21. Meier B, Blaauw Y, Khattab AA, et al. EHRA/EAPCl expert consensus statement on catheter-based left atrial appendage occlusion. Eurolntervention 2015; 10: 1109-25.

22. Hart RG, Pearce LA, Aguilar MI. Meta-analysis: antithrombotic therapy to prevent stroke in patients who have nonvalvular atrial fibrillation. Ann Intern Med 2007; 146: 857-67.

23. Mant J, Hobbs FD, Fletcher K, et al. Warfarin versus aspirin for stroke prevention in an elderly community population with atrial fibrillation (the Birmingham atrial fibrillation treatment of the aged study, BAFTA): a randomised controlled trial. Lancet 2007; 370: 493-503.

24. Connolly SJ, Eikelboom J, Joyner C, et al. Apixaban in patients with atrial fibrillation. N Engl J Med 2011; 364: 806-17.

25. Sato H, Ishikawa K, Kitabatake A, et al. Low-dose aspirin for prevention of stroke in low-risk patients with atrial fibrillation: Japan atrial fibrillation stroke trial. Stroke 2006; 37: 447-51.

26. Rash A, Downes T, Portner R, et al. A randomised controlled trial of warfarin versus aspirin for stroke prevention in octogenarians with atrial fibrillation (WASPO). Age Ageing 2007; 36: 151-6.

27. van Kruijsdijk RC, Visseren FL, Ridker PM, et al. Individualised prediction of alternate-day aspirin treatment effects on the combined risk of cancer, cardiovascular disease and gastrointestinal bleeding in healthy women. Heart 2014 Dec 4. pii: heartjnl-2014-306342. doi: 10.1136/heartjnl-2014-306342. 
28. Seshasai SR, Wijesuriya S, Sivakumaran R, et al. Effect of aspirin on vascular and nonvascular outcomes: meta-analysis of randomized controlled trials. Arch Intern Med 2012; 172: 209-16.

29. Ikeda Y, Shimada K, Teramoto T, et al. Low-dose aspirin for primary prevention of cardiovascular events in Japanese patients 60 years or older with atherosclerotic risk factors: a randomized clinical trial. JAMA 2014; 312: 2510-20.

30. Perk J, De Backer G, Gohlke H, et al. European guidelines on cardiovascular disease prevention in clinical practice (version 2012). the fifth joint task force of the European society of cardiology and other societies on cardiovascular disease prevention in clinical practice (constituted by representatives of nine societies and by invited experts). Eur Heart J 2012; 33: 1635-701. 